\title{
Correction to: In vivo imaging of type 1 diabetes immunopathology using eye-transplanted islets in NOD mice
}

\author{
Midhat H. Abdulreda ${ }^{1,2,3,4}$ • R. Damaris Molano ${ }^{1}$ • Gaetano Faleo ${ }^{1}$ • Maite Lopez-Cabezas ${ }^{1}$ • Alexander Shishido ${ }^{1}$. \\ Ulisse Ulissi $^{1}$ • Carmen Fotino ${ }^{1}$ • Luis F. Hernandez ${ }^{1}$ • Ashley Tschiggfrie ${ }^{1}$ • Virginia R. Aldrich ${ }^{1}$. \\ Alejandro Tamayo-Garcia $^{1,5}$. Allison S. Bayer ${ }^{1,3}$. Camillo Ricordi ${ }^{1,2,3,6,7}$ - Alejandro Caicedo ${ }^{5}$ Peter Buchwald $^{1,8}$. \\ Antonello Pileggi ${ }^{1,2,3,6,9}$. Per-Olof Berggren ${ }^{1,2,7,10}$
}

Published online: 12 June 2019

(C) Springer-Verlag GmbH Germany, part of Springer Nature 2019

\section{Correction to: Diabetologia}

https://doi.org/10.1007/s00125-019-4879-0

Unfortunately there is a mistake in the presentation of the affiliations in this paper. The NIH affiliation for Antonello Pileggi should have been captured as a 'present address'. The corrected affiliations are listed here. Dr Pileggi notes that this article was prepared while he was employed at the University of Miami. He is currently employed at NIH/ Center for Scientific Review. The opinions expressed in this article are the authors' own and do not reflect the view of the National Institutes of Health, the Department of Health and Human Services, or the United States government.

Publisher's note Springer Nature remains neutral with regard to jurisdictional claims in published maps and institutional affiliations.

The online version of the original article can be found at https://oi.org/ 10.1007/s00125-019-4879-0

Midhat H. Abdulreda

mabdulreda@miami.edu

Peter Buchwald

pbuchwald@miami.edu

$\triangle$ Antonello Pileggi

antonello.pileggi@nih.gov

$\triangle$ Per-Olof Berggren per-olof.berggren@ki.se

1 Diabetes Research Institute and Cell Transplant Center, University of Miami Miller School of Medicine, 1450 NW 10th Ave,

Miami, FL 33136, USA

2 Department of Surgery, University of Miami Miller School of Medicine, Miami, FL, USA

3 Department of Microbiology and Immunology, University of Miami Miller School of Medicine, Miami, FL, USA
Department of Ophthalmology, University of Miami Miller School of Medicine, Miami, FL, USA

5 Department of Medicine, University of Miami Miller School of Medicine, Miami, FL, USA

6 Department of Biomedical Engineering, University of Miami, Coral, Gables, FL, USA

7 Diabetes Research Institute Federation, Hollywood, FL, USA

8 Department of Molecular and Cellular Pharmacology, University of Miami Miller School of Medicine, Miami, FL, USA

9 Present address: Center for Scientific Review, National Institutes of Health, 6701 Rockledge Drive, Bethesda, MD 20892, USA

10 The Rolf Luft Research Center for Diabetes and Endocrinology, Karolinska Institutet, Karolinska University Hospital L1, SE-17176 Stockholm, Sweden 